\title{
Strength Training for the Prevention and Treatment of Dynapenia
}

\author{
Daniel P Williams* \\ Department of Kinesiology, University of La Verne, California, USA
}

*Corresponding author: Daniel P Williams, Department of Kinesiology, University of La Verne, California, USA, Tel: +1 9094484110; E-mail: dwilliams2@laverne.edu

Received Date: 15 July, 2017; Accepted Date: 18 October, 2017; Published Date: 31 October, 2017

\begin{abstract}
Background: The age-related loss of neuromuscular strength is now called dynapenia. Because strength training lies at the cornerstone of all efforts aimed at the prevention and treatment of dynapenia, the present review focuses on critically assessing strength training recommendations, systematic reviews, and meta-analyses for older adults. To provide additional rationale, the review also examines the demographics of aging and the health consequences of dynapenia.
\end{abstract}

Findings: Our domestic and global populations are rapidly growing older. By the turn of the century, one-third of the population of the USA is projected to be aged 60 or more years. Dynapenia is associated with mobility impairments, physical disabilities, cognitive declines, loss of independence, and higher risks for chronic disease morbidity and mortality. Most contemporary preventive and therapeutic strength training recommendations advise training 2-3 days per week on non-consecutive days completing 5-10 exercises involving the major muscle groups and initially starting with 1 set of 10-15 repetitions for each exercise. However, systematic reviews and meta-analyses report that greater strength gains in older adults require moderate to high training intensities ranging from $60-80 \%$ of a 1-Repetition Maximum (RM) and longer training durations of at least one year.

Conclusion: Moderate-to-high intensity strength training done two or more times per week with adequate progression and periodization is a lifelong lifestyle that is needed to sustain adequate neuromuscular strength to slow dynapenia, and quite possibly, to extend the health span of human life.

\section{Keywords}

Aging; Dynapenia; Health Span; Intensity; Older Adults; Strength Training

\section{Rationale}

In 2008, Clark and Manini introduced the term dynapenia to refer to the decline in strength that accompanies aging [1]. As they explain, dynapenia is a Greek word that translates as "poverty of strength." Strength is defined as the maximal force or torque developed voluntarily [2]. Contrary to common belief, strength is a neuromuscular rather than a purely muscular variable. For instance, developing maximal voluntary force or torque involves the coordinated activation of the brain, the spinal cord, the motor neurons, and the skeletal muscle fibers. In 2008, Clark and Manini made an important distinction between dynapenia and sarcopenia. Sarcopenia is the age-related loss of skeletal muscle mass [1]. Sarcopenia is another Greek word that translates as "poverty of flesh". Because strength has neuromuscular determinants, dynapenia cannot solely result from or be caused by sarcopenia [1].

In fact, dynapenia occurs at a faster rate than sarcopenia [3-5]. For instance, the age-related loss of strength may be 2-5 times faster than the age-related loss of skeletal muscle mass [6]. Moreover, low strength is more strongly and consistently associated with poor physical performance, functional limitation, mobility impairment, and disability than low skeletal muscle mass in older adults [7-9]. Because strength training is an essential treatment for the prevention and treatment of dynapenia, the present review focuses on critically assessing strength training recommendations, systematic reviews, and meta-analyses for older adults. Because the age distributions of our domestic and global populations are shifting, the review also examines the demographics of aging and the health consequences of dynapenia.

\section{Demographics of Aging}

The popular press in the United States of America (USA) has recently addressed the demographic projections that point to an aging domestic population $[10,11]$. However, this "greying" of America is also a global phenomenon. For instance, the most recent estimates from the United Nations (UN) report that $13 \%$ of the world population is 60 or more years of age in 2017 (Figure 1). The UN projections estimate that individuals aged $60+$ years will grow to $21 \%$ of the world population in 2050 and to $28 \%$ of the world population in 2100 (Figure 1). To an even greater degree, individuals aged $60+$ years comprise $22 \%$ of the USA population 
Citation: Williams DP (2017) Strength Training for the Prevention and Treatment of Dynapenia. J Bone Muscles Stud 2017: 13-21. DOI : https://doi.org/10.29199/2637-7039/BOMS-101015.

in 2017 (Figure 1). They will grow to $28 \%$ of the USA population in 2050 and to $33 \%$ of the USA population in 2100 (Figure 1). The biggest factors affecting the aging global and domestic populations are declining birth rates and higher life expectancies [12].
Globally, life expectancy at birth is expected to rise from 70.8 years in 2015-2020 to 82.6 years in 2095-2100 (Figure 2). By comparison, in the USA, life expectancy at birth is expected to rise from 78.9 years in 2015-2020 to 89.6 years in 2095-2100 (Figure 2).

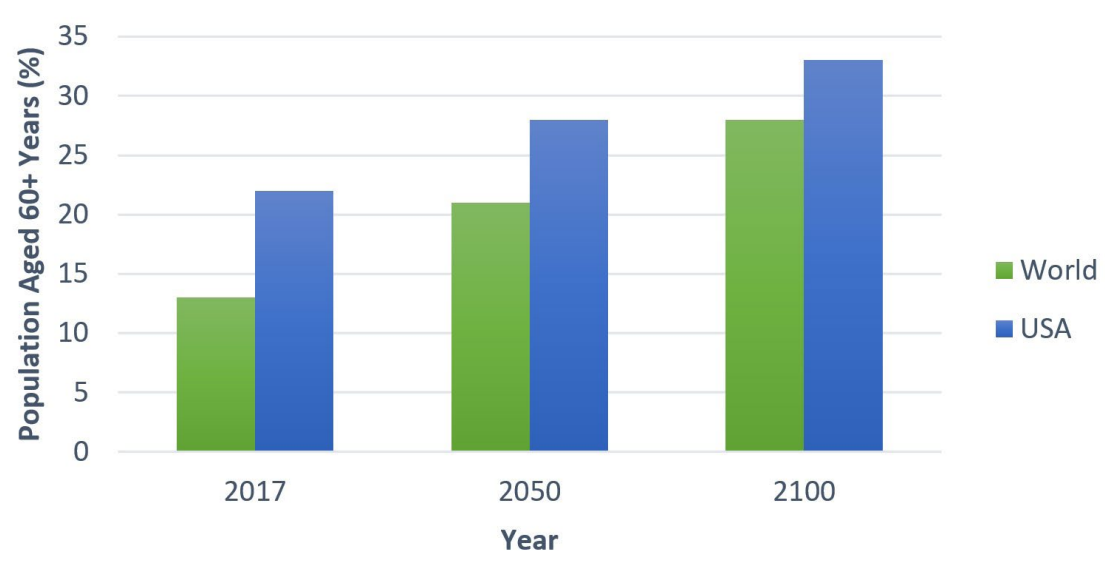

Figure 1: Projections of global and domestic population aging [12].

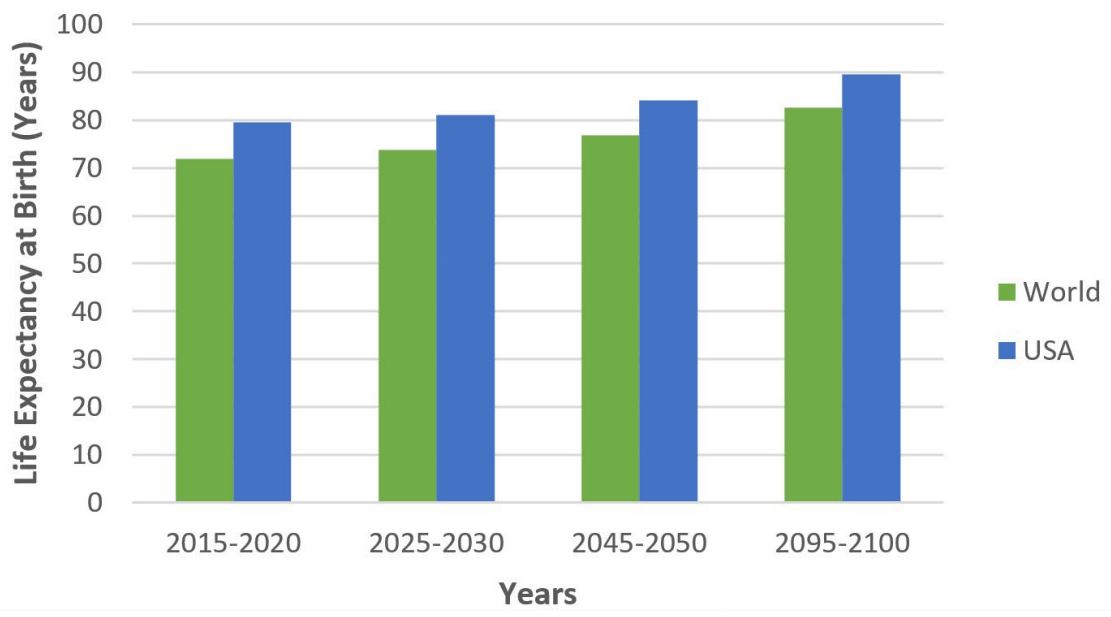

Figure 2: Projections of global and domestic life expectancy [12].

The domestic population aging will have enormous social and economic impacts in the USA. As a work force ages, it becomes less productive, as a larger proportion of the population will be retired $[10,11]$. In the USA, Medicare and Social Security depend on taxed income from a large and necessarily younger work force $[10,11]$. If American birth rates do not rise above current projections, the need for younger workers will be increasingly dependent on immigration to fill employment needs and to support greater numbers of retired Americans drawing on Medicare and Social Security benefits $[10,11]$. Thus, the future work force will necessarily become increasingly diverse and multicultural due to its increasing dependence on immigration $[10,11]$. In brief, domestic population aging will usher in greater social changes in American society as a work force necessity and economic imperative [10,11].
Furthermore, the work force needs are shifting to serve the burgeoning aging population, as the fastest growing occupations are in a health care industry that is rapidly expanding its geriatric services $[10,11]$. It is not yet known how America will handle its current and future health care crisis of increasing health insurance demands, spiraling health care costs, and population aging.

Due to the economic impact of our aging population, public health efforts must focus on strategies that extend the "health span" of human life [13]. Health span extension aims to prolong the healthy period of life and to shorten the unhealthy period of life marked by disabilities and chronic diseases to a brief period at the end of life [13]. Although medical advances help to explain the previously discussed increases in life expectancy, 
individuals today are more likely surviving longer with disabilities and chronic diseases rather than enjoying a longer health span [13]. Health span extension is beyond the focus of this review because it seeks to slow the biological processes of aging [13]. For instance, the Google company, Calico, was launched to find viable treatments for the biological challenges of aging itself [14]. In brief, health span extension will likely involve a combination of exercise, diet, pharmaceutical, and nutraceutical strategies aimed at optimizing physiological function. Selection of various combinations of intervention strategies may occur, in part, by better understanding how sex, ethnic, and genetic differences moderate the individual responses to the combined intervention strategies [13]. Nevertheless, regular physical activity along with ideal dietary intakes represent first line approaches for preserving function as individuals grow older $[13,15]$. In fact, exercise is the only intervention, to date, that has consistently reduced functional declines in older adults [15]. However, exercise is not a panacea, especially without the other intervention strategies, for preserving physical function and preventing disability [15]. With regard to aging, we need to refine which type, intensity and volume of exercise helps to prevent and treat each specific physiological decline like neuromuscular strength [13].

\section{Health Consequences of Dynapenia}

There are many health consequences of dynapenia. For instance, low strength is associated with mobility impairments, poor physical performance in activities of daily living, physical disability and worsening physical disability [7-9,16,17]. In brief, dynapenia leads to poor neuromuscular function, which may increase the risk for losing independence in older adults by up to 6-fold [18]. In addition, age-related reductions in handgrip strength are associated with age-related cognitive declines in older adults [19]. Cognitive declines represent another common way that older adults lose independence and become dependent on caregivers.

Low strength is also associated with a greater risk for skeletal and cardiometabolic disease morbidity. For instance, low strength increases the risk for osteopenia or osteoporosis [20], myocardial infarction [21], stroke [21], and type 2 diabetes [22]. Importantly, the associations of low strength with higher myocardial infarction and stroke risks were independent of a host of potential confounding factors including dietary intake and physical activity [21]. However, the association between low strength and a higher risk for type 2 diabetes involves an interaction between dynapenia and obesity [22]. Individuals with dynapenic obesity, who had a low handgrip strength and a high body mass index, were 4.9 times as likely to develop type 2 diabetes as non-obese individuals with high handgrip strength after adjusting for age, sex, smoking, alcohol intake, physical activity, symptoms of depression, and prevalent cardiovascular disease [22].

Furthermore, low strength is also associated with a greater risk for all-cause [7,21,23-25], cancer [25], and cardiovascular $[21,24]$ mortality. In fact, Leong et al., reported that low grip strength was a stronger predictor of all-cause and cardiovascular mortality than systolic blood pressure [21]. The exact physiological mechanisms that may link dynapenia with the above morbidity and mortality risks are not entirely known. Nevertheless, Ruiz et al., [25] reported that the associations of low strength with higher risks for all-cause and cancer mortality were independent of age, physical activity, smoking, alcohol intake, body mass index, baseline medical conditions, family history of cardiovascular disease, and even cardiorespiratory fitness [25]. Thus, it is likely that neuromuscular strength may affect all-cause and cancer mortality risks, at least in part, through different mechanisms than cardiorespiratory fitness [25].

In brief, dynapenia is associated with deteriorating neuromuscular function, mobility impairments, physical disabilities, advancing cognitive declines, loss of independence, and higher risks for chronic disease morbidity and mortality. Learning and understanding the physiological mechanisms by which dynapenia may contribute to such a wide and devastating range of health consequences would help immensely in selecting complementary prevention and treatment strategies for specific individuals. To date, most of the speculative mechanisms narrowly focus on sarcopenia. For instance, skeletal muscle is a vital metabolic reserve that enhances survival from chronic wasting diseases like cancer or heart failure. Skeletal muscle is also the largest organ in the body for glucose metabolism and storage, so it plays an important role in preserving insulin sensitivity. Moreover, skeletal muscle's tensile force is a potent stimulus for building, remodeling, and strengthening bone tissue. However, dynapenia is a much stronger predictor of mobility impairment, disability, and mortality than sarcopenia [7-9]. The mechanisms of dynapenia include problems with neural activation, reductions in the intrinsic force-generating capacity of skeletal muscle, and skeletal muscle wasting [8]. Thus, future studies need to more broadly investigate the physiological explanations for the multitude of health consequences of dynapenia. More importantly, progressive resistance exercise training, or strength training, must now be viewed as a necessary lifestyle behavior for preventing and treating dynapenia in our increasingly aging population.

\section{Strength Training Recommendations}

The current preventive physical activity recommendations for healthy adults and older adults advise engaging in strength training on two or more days per week $[26,27]$. In a longitudinal cohort of US older adults followed from 1997 to 2011, those who already met the 2007 strength training frequency recommendation in 1997-1999 were slightly younger, more likely to be married, white, male, more highly educated, have a normal body weight, engage in aerobic exercise, and abstain from alcohol and tobacco than those who did not meet the recommendation [28]. In addition, those who met the future recommendation were less likely to have diabetes and hypertension than those who did not meet the recommendation [28]. Even after adjusting for all of the demographic, health behavior, and medical history differences, those who met the strength training frequency recommendation still had a $19 \%$ lower odds of all-cause mortality than those who did not meet the recommendation [28]. Therefore, older adults who were already following the recommendations in the late 1990s before they were released had better health behaviors, 
fewer comorbid conditions, and lower mortality risk than those who did not follow the recommendations [28]. Unfortunately, the less educated and more ethnically diverse segments of the older adult population with poorer medical histories and health behaviors are not engaging in regular strength training. However, the most physically inactive individuals with the lowest levels of strength and the highest mortality risks have the greatest capacity to improve their strength and to reduce their health risks with regular training.

In another study, only $16.1 \%$ of 6,763 adults aged 65 or older self-reported that they met the strength training frequency recommendation in 2011, which was four years after the recommendation was released [29]. Therefore, despite the "Exercise is Medicine" initiative that encourages physicians to recommend physical activity to their patients [30], the recommendations were potentially reaching or convincing only $16 \%$ of the Americans sampled. In brief, more effective and creative ways are desperately needed to identify and to overcome the barriers to regular participation in strength training for older adults.

Some of the basic principles of strength training that are needed to understand the recommendations include progressive overload, specificity of training, periodization of training, and choice of exercises [2]. To become stronger, the exercise demands must be continually increased, so that the neuromuscular system is progressively overloaded. One of the simplest ways to ensure progressive overload is to train with a Repetition Maximum (RM). For instance, if an individual can bench press a maximum of $50 \mathrm{~kg}$ eight times without rest, then this is her or his $8-\mathrm{RM}$ for that exercise. After strength gains occur over several weeks of training, the 8-RM for the bench press may increase from 50 to $55 \mathrm{~kg}$ [2]. Another principle of strength training is specificity, which means that the upper body motor units recruited in the bench press will not train the lower body motor units. This is why training programs are designed with specific exercises for each of the major skeletal muscle groups [2]. The downsides to pursuing the progressive overload principle with a constant repetition range for several weeks while the weight or resistance is increased only as strength is gained include protracted strength plateaus, boredom, and overtraining [2]. The remedy for constant strength training progressions is periodization of training, which allows for optimal variation of training. In brief, periodization is a systematic manipulation of training exercises, intensity, and volume (numbers of sets and repetitions) to provide the body with the requisite recovery periods and alterations in training stimuli needed to optimize strength gains [2]. Finally, the choice of strength training exercises optimally incorporates a combination of multiple- and single-joint exercises that are performed bilaterally and unilaterally [2]. A bench press is a multiple-joint exercise that moves both the shoulder and the elbow joints, and it is typically performed bilaterally with a barbell. By contrast, a biceps curl is a single-joint exercise that only moves the elbow joint. A biceps curl can be performed bilaterally with a barbell or unilaterally with a dumbbell. However, its unilateral performance with a dumbbell can be helpful for correcting bilateral strength deficits (a weaker non-dominant vs. dominant arm) because it prevents the stronger arm from assisting the weaker arm with the movement [2].

The various preventive, therapeutic, and optimal strength training recommendations are summarized below (Table 1). There are many similarities among the strength training recommendations. In fact, the preventive recommendations for older adults, the therapeutic recommendations for individuals with type 2 diabetes, and the therapeutic recommendations for Cardiovascular Disease (CVD) patients are nearly identical (Table 1). This is important because many older adults have cardiometabolic disease and need to be able to integrate preventive and therapeutic recommendations. Taken together, the preventive recommendation for older adults [27], the therapeutic recommendation for type 2 diabetics [31], and the therapeutic recommendation for CVD patients [32] advise strength training 2-3 days per week on non-consecutive days completing 5-10 exercises involving the major muscle groups and initially starting with 1 set of 10-15 repetitions for each exercise.

The ACSM optimal training recommendations for healthy adults [33] singularly incorporates all of the basic principles of strength training and its progression (Table 1). For instance, the optimal recommendations are designed to progress a novice at strength training through the intermediate and advanced stages of strength training [33]. Fortunately, Law et al., have recently applied many of the progression principles from the optimal recommendations to the senior resistance exerciser [35]. In fact, Law et al., provide two-phase sample resistance training programs for the prevention and treatment of dynapenia for a beginner, an intermediate, and an advanced senior resistance exerciser [35]. While the ACSM optimal recommendations [33] may be more appealing for athletes or other highly devoted exercisers, these recommendations might not be reasonably prescribed to senior exercisers who are unable to devote the requisite time for more prolonged and frequent bouts of strength training. Nevertheless, ACSM's recommended periodization principles for unilateral and bilateral training [33] can be beneficial if incorporated into a resistance training program for senior exercisers. A periodized resistance training program helps to overcome strength plateaus while ensuring long-term strength gains, whereas unilateral movements with a dumbbell rather than bilateral movements with a barbell may be needed to correct lifelong bilateral strength deficits [2].

When reviewing the preventive and therapeutic recommendations for strength training (Table 1), it is important to remember that they are designed to be simple yet effective at transitioning sedentary individuals into regular exercisers. In addition, all of the preventive and therapeutic strength training recommendations form only one part of an overall physical activity program that includes aerobic activity and may also include flexibility and balance training. Thus, the strength training recommendation needs to be simple, concise, and easily communicated for widespread dissemination (e.g., at a physician visit). Furthermore, the recommendation cannot overwhelm or intimidate a physically inactive individual from beginning an exercise program. Moreover, attempts to increase training intensity too soon can lead to excessive delayed-onset muscle soreness and discontinuation of training. Nevertheless, if the goal is to prevent and treat dynapenia, then the current preventive 
Citation: Williams DP (2017) Strength Training for the Prevention and Treatment of Dynapenia. J Bone Muscles Stud 2017: 13-21.

and therapeutic strength training recommendations may be too improve strength, particularly for long-term adopters, who have general and lack all of the requisite training principles to sufficiently successfully incorporated strength training into their lifestyles.

\begin{tabular}{|c|c|c|c|}
\hline Population & Strength & Training & \\
\hline \multicolumn{4}{|l|}{ Recommendation } \\
\hline Organization(s) & Frequency & Exercises & Load and Volume \\
\hline \multicolumn{4}{|l|}{ Healthy Adults } \\
\hline $\begin{array}{l}\text { Physical Activity } \\
\text { ACSM/AHA [26] }\end{array}$ & $\geq 2 \mathrm{~d} \cdot \mathrm{wk}^{-1}$ & $\begin{array}{l}\text { 8-10 exercises } \\
\text { involving the major } \\
\text { muscle group }\end{array}$ & $\begin{array}{l}8-12 \text { reps resulting in volitional } \\
\text { fatigue }\end{array}$ \\
\hline \multicolumn{4}{|l|}{ Older Adults } \\
\hline $\begin{array}{l}\text { Physical Activity } \\
\text { ACSM/AHA [27] }\end{array}$ & $\geq 2 \mathrm{~d} \cdot \mathrm{wk}^{-1}$ & $\begin{array}{l}\text { 8-10 exercises } \\
\text { involving the major } \\
\text { muscle groups }\end{array}$ & $\begin{array}{l}10-15 \text { reps at } 5-8 \text { on } 10 \text {-point scale for } \\
\text { intensity of effort }\end{array}$ \\
\hline \multicolumn{4}{|l|}{ Healthy Adults } \\
\hline $\begin{array}{l}\text { Optimal Training [33] } \\
\text { ACSM }\end{array}$ & 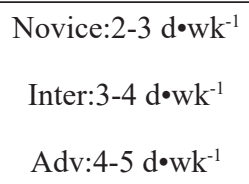 & $\begin{array}{l}\text { Bilateral and unilateral single-and mul- } \\
\text { tiple-joint exercises for all }\end{array}$ & $\begin{array}{l}\text { 1-3 Sets x 8-12 RM } \\
\text { Mult Sets x 1-12 RM periodized } \\
\text { Mult Sets x 1-12 RM periodized }\end{array}$ \\
\hline \multicolumn{4}{|l|}{ Type 2 Diabetics } \\
\hline $\begin{array}{l}\text { Physical Activity } \\
\text { ADA/ACSM [31] }\end{array}$ & $2-3 d \cdot w^{-1}$ & $\begin{array}{l}\text { 5-10 machine and free weight exercises } \\
\text { involving the major muscle groups }\end{array}$ & $\begin{array}{l}\text { 1-4 Sets x } 10-15 \text { reps initially to } 1-4 \\
\text { Sets x } 8-10 \text { reps eventually at } 50-80 \% \\
\text { of } 1-\mathrm{RM} \text { load }\end{array}$ \\
\hline \multicolumn{4}{|l|}{ Patients with OA } \\
\hline $\begin{array}{l}\text { Exercise } \\
\text { AGS [34] }\end{array}$ & $2-3 d \cdot w^{-1}$ & $\begin{array}{l}\text { Exercises involving } \\
\text { the major muscle } \\
\text { groups and stable } \\
\text { joints }\end{array}$ & $\begin{array}{l}10-15 \text { reps at } 40 \% 1-\mathrm{RM} ; 8-10 \text { reps at } \\
40-60 \% 1-\mathrm{RM} ; 6-8 \text { reps at }>60 \% 1-\mathrm{RM}\end{array}$ \\
\hline \multicolumn{4}{|l|}{ CVD Patients } \\
\hline $\begin{array}{l}\text { Resistance Exercise } \\
\text { AHA [32] }\end{array}$ & $2-3 d \cdot w k^{-1}$ & $\begin{array}{l}\text { 8-10 exercises } \\
\text { involving the major } \\
\text { muscle groups }\end{array}$ & 1 Set $x$ 10-15 reps \\
\hline
\end{tabular}

Table 1: Preventive, optimal, and therapeutic strength training recommendations.

ACSM=American College of Sports Medicine; ADA=American Diabetes Association; Adv=Advanced; AGS=American Geriatrics Society; $\mathrm{AHA}=$ American Heart Association; $\mathrm{CVD}=$ Cardiovascular disease Inter=Intermediate; Mult=Multiple; $\mathrm{OA}=\mathrm{Osteoarthritis;} \mathrm{reps=}$ Repetitions; RM=Repetition Maximum.

\section{Strength Training Research}

When gathering medical evidence that is used to inform clinical practice recommendations, it is helpful to consider a "hierarchy of evidence" that can be conceptualized as a pyramid [36]. At the base of the pyramid are ideas, which may include anecdotal data and expert opinion. At the apex of the pyramid are published synthesis research articles, which include systematic reviews and meta-analyses that ideally synthesize and analyze randomized controlled trials in a selected area of clinical practice [36]. Notable systematic reviews and meta-analyses of the effects of resistance training on strength in older adults are summarized below (Table 2).

The most consistent finding from the systematic reviews and meta-analyses is that resistance training-related strength gains in older adults are affected by intensity (Table 2). Higher intensity training programs yielded larger strength gains in 4 out of 5 of the systematic reviews and meta-analyses (Table 2). Furthermore, the one analysis that did not find an effect of intensity on strength gains included only 3 of 15 studies that trained at lower intensities 
Citation: Williams DP (2017) Strength Training for the Prevention and Treatment of Dynapenia. J Bone Muscles Stud 2017: 13-21.

\begin{tabular}{|c|c|c|}
\hline Reference & Included Studies & Main Finding(s) \\
\hline$[37]$ & $\begin{array}{l}\text { N=25 Randomized Controlled Trials } \\
\text { (RCT) with } 819 \text { participants aged } \geq 60 \text { yrs. }\end{array}$ & $\begin{array}{l}\text { The largest Resistance Training (RT) effects on Upper Body (UB) and Lower } \\
\text { Body (LB) strength were observed for durations of } 50-53 \text { wks., intensities } \\
\text { of } 70-79 \% \text { of } 1-\mathrm{RM} \text {, and total time under tension of } 6 \text { s. }\end{array}$ \\
\hline$[38]$ & $\begin{array}{c}\mathrm{N}=73 \text { RCT with } 3,059 \text { participants with } \\
\text { mean or } \geq 60 \text { yrs. }\end{array}$ & $\begin{array}{c}\text { The largest RT effects on LB strength were observed when higher vs. lower } \\
\text { intensities, when healthy vs. unhealthy participants, and when non-blinded } \\
\text { vs. blinded assessors were used. }\end{array}$ \\
\hline$[39]$ & $\begin{array}{c}\mathrm{N}=47 \text { studies with } 1,079 \text { participants aged } \\
\qquad 50 \text { yrs. }\end{array}$ & $\begin{array}{c}\text { For each incremental increase in RT intensity from }<60 \% \text { of } 1-\mathrm{RM} \text { to } 60- \\
69 \% \text { of } 1-\mathrm{RM} \text { to } 70-79 \% \text { of } 1-\mathrm{RM} \text { to } \geq 80 \% \text { of } 1-\mathrm{RM} \text {, the mean UB and LB } \\
\text { strength increased by } 5.3 \% \text {. }\end{array}$ \\
\hline$[40]$ & $\begin{array}{c}\mathrm{N}=15 \mathrm{RCT} \text { with } 528 \text { participants aged } \\
\geq 55 \mathrm{yrs}\end{array}$ & $\begin{array}{l}\text { RT yielded larger LB strength gains over longer }(24-52 \text { wks.) vs. shorter } \\
\text { (8-18 wks.) durations. LB strength gains were not affected by RT differences } \\
\text { in the number of sets, weekly frequency, or intensity. }\end{array}$ \\
\hline$[41]$ & $\begin{array}{c}\mathrm{N}=29 \mathrm{RCT} \text { with } 1,313 \text { participants aged } \\
\geq 60 \text { yrs. }\end{array}$ & $\begin{array}{l}\text { The largest RT effects on LB strength were observed for intensities of 60- } \\
\qquad 80 \% \text { of 1-RM. }\end{array}$ \\
\hline
\end{tabular}

Table 2: The effects of resistance training on strength in older adults.

$(<60 \% 1-\mathrm{RM})$, so it may have selected studies with inadequate variability in training intensities to detect an effect of intensity on strength gains [40]. The common finding regarding the efficacy of higher intensity training ranging from $60-80 \%$ of a 1-RM (Table 2 ) is an important consideration because many of the preventive and therapeutic strength training recommendations advise older adults to begin training at $10-15$ repetitions per exercise with little to no specific guidance for intensity or progression (Table 1). Because higher repetition numbers necessitate lower resistance loads and intensities, many of the preventive and therapeutic recommendations aimed at older and/or diseased adults may need to consider providing more explicit and detailed advice about gradually reducing the repetition number and increasing the intensity over time to ensure adequate strength gains. Among the preventive and therapeutic recommendations, the therapeutic strength training recommendations for type 2 diabetics provide the most explicit and detailed advice about how to progress within an intensity range that is closest to the effective intensity range of the meta-analyses (Table 1) [31].

Of all of the selected meta-analyses (Table 2), Borde et al., come closest to providing a complete exercise prescription [37]. For instance, their analysis revealed that training at $70-79 \%$ of $1-\mathrm{RM}$ with each repetition lasting 6 seconds over a training period of 50-53 weeks was most effective for strength gains in adults aged 60 or more years. Because the repetition duration or time under tension affects metabolic changes, motor unit recruitment, and motor unit firing rates during strength training, it is an important variable to consider not only for implementing strength training programs but also for researchers to report in their studies [37]. Furthermore, the efficacy of long duration training was corroborated by another meta-analysis [40]. Long duration training for strength gains not only reinforces the necessity of adequate progression in a training program $[33,35]$, but it also reinforces the notion that lifelong strength training should be adopted to adequately slow dynapenia $[42,43]$. Although the other training variables identified by Borde et al., were of insufficient statistical power, they suggest that 60 seconds of rest between sets, a training frequency of 2 sessions per week, 2-3 sets per exercise, 7-9 repetitions per set and 4 seconds between repetitions may be best for strength gains in older adults [37]. However, future trials and meta-analyses are required to confirm or refute these training suggestions.

Future trials and meta-analyses are also needed to address the findings and conclusion from the Liu and Latham report [38]. Most notably, resistance training yielded greater strength gains in healthy than in unhealthy older adults. However, there was a relative paucity of studies that included older adults with specific health problems, so they could not examine the effects of resistance training in older adults in distinct clinical populations. Moreover, resistance training-related strength gains were greater in studies using non-blinded vs blinded assessors. This is an important yet common problem that compromises the internal validity of strength training trials. Future trials need to use less biased technicians to assess strength changes, who neither deliver the strength training intervention nor know which study participants are in the strength training or the control group. Finally, Liu and Latham caution that there was insufficient evidence to comment on the risks of strength training [38]. Thus, investigators need to consistently report the adverse events and injuries that occurred in their trials even if there weren't any. Compelling safety data will be needed to consider all of the implications of adding greater details about training progressions to the present preventive and therapeutic strength training recommendations (Table 1). For instance, the optimal recommendations advocate training progressions with a greater variety of exercises and periodized phases of increases and decreases in training intensities and volumes to overcome the inevitable plateaus in strength gains [33]. We need to change the vernacular and practice of strength training away from exercise "routines" to exercise "plans," which are more mutable and evolving. Neuromuscular strength gains are built on responses to a succession of new training challenges and stimuli.

\section{Future Directions}

Mobile and wearable devices, especially wearable activity 
monitors like many popular fitness trackers, have the potential to improve physical activity assessment, advance physical activity counseling, improve motivation and adherence, and streamline referral to community resources for chronic disease risk reduction interventions $[44,45]$. Many commercially available fitness trackers count steps, measure distance covered or climbed, and track the frequency, intensity, and duration of such continuous endurance activities as walking, hiking, and running. However, these fitness trackers do not adequately quantify strength training, which is a highly intermittent activity where steps taken, distance covered, exercise duration, and exercise heart rates are not meaningful ways to assess strength training intensity or volume (sets x repetitions). Fitness trackers designed specifically for strength training have only recently been assessed for reliability and validity. For instance, one notable fitness tracker is capable of counting strength training repetitions as well as measuring movement velocities during the concentric phase of strength training exercises [46]. The ability to measure movement velocities during strength training with a wearable device may be an important advance in assessing strength training intensity. For instance, strength training movement velocities are capable of estimating the 1-repetition maximum in a less demanding way without performing a maximal lift [46]. Furthermore, lower percentages of movement velocity loss during each set of strength training are associated with greater strength gains [46]. In brief, the potential is high for wearable activity monitors, but they require additional research and development, particularly for tracking and quantifying strength training exercise.

Physical activity recommendations may soon be expanded from quantifying how much endurance and strengthening exercise to do each week to include how much sitting or sedentary time to avoid as well as how much fitness to attain [47]. There is a well-documented and disturbing global reduction in metabolic equivalents of physical activity that is accompanied by simultaneous increases in sedentary time from the 1960 s to the middle to late 2000 s, which threaten global health [48]. Thus, providing the public with minimal weekly physical activity recommendations is not enough to combat otherwise sedentary lifestyles due to societal dependence on automobiles for transportation, sedentary occupations at computer workstations, and televised entertainment. Moreover, fitness improvements are a stronger predictor of reductions in chronic disease morbidity and mortality than physical activity increases [47]. More research is needed before we're able to better refine the weekly dose of strength training needed to prevent and treat dynapenia, prescribe how much weekly sitting and sedentary time to avoid, and establish strength goals to attain for specific exercises. Nevertheless, the next iteration of the preventive health recommendations for exercise will likely include a more unified and comprehensive message for how the public can better avoid three vital and independent risk factors of insufficient physical activity, too much time spent sitting, and low physical fitness [47].

\section{Summary and Conclusion}

Our domestic and global populations are rapidly growing older. To prevent the economic consequences of our greying populations, we need to more effectively use strength training exercise to slow the age-related loss of neuromuscular strength, which is now called dynapenia. Dynapenia, in turn, is associated with deteriorating neuromuscular function, physical disabilities, advancing cognitive declines, loss of independence, and higher risks for chronic disease morbidity and mortality. Contemporary preventive and therapeutic strength training recommendations are aimed at getting the overwhelming majority of sedentary older adults to adopt a regular exercise habit to become stronger. However, research suggests that many of the training recommendations may lack the intensity and the progression needed to ensure sufficient strength gains over time. Moderate-to-high intensity strength training done two or more times per week with adequate progression and periodization is a lifelong lifestyle that is needed to sustain adequate neuromuscular strength to slow dynapenia, and quite possibly, to extend the health span of human life.

\section{References}

1. Clark BC, Manini TM (2008) Sarcopenia =/= dynapenia. J Gerontol A Biol Med Sci 63: 829-834.

2. American College of Sports Medicine (2014)ACSM's Resource Manual for Guidelines for Exercise Testing and Prescription. In: Swain DP, ACSM, Brawner CA (eds.). ACSM's Resource Manual for Guidelines for Exercise Testing and Prescription. (7thedn), Lippincott Williams \& Wilkins, Philadelphia, USA. 360: 483-485.

3. Delmonico MJ, Harris TB, Visser M, Park SW, Conroy MB, et al. (2009) Longitudinal study of muscle strength, quality, and adipose tissue infiltration. Am J Clin Nutr 90: 1575-1585.

4. Goodpaster BH, Park SW, Harris TB, Kritchevsky SB, Nevitt M, et al. (2006) The loss of skeletal muscle strength, mass, and quality in older adults: the Health, Aging, and Body Composition Study. J Gerontol A Biol Med Sci 61: 1059-1064.

5. Kennis E, Verschueren S, Van Roie E, Thomis M, Lefevre J, et al. (2014) Longitudinal impact of aging on muscle quality in middle-aged men. Age (Dordr) 36: 9689.

6. Mitchell WK, Williams J, Atherton P, Larvin M, Lund J, et al. (2012) Sarcopenia, dynapenia, and the impact of advancing age on human skeletal muscle size and strength: a quantitative review. Front Physiol 3: 260.

7. Kim YH, Kim KI, Paik NJ, Kim KW, Jang HC, et al. (2016) Muscle strength: a better index of low physical performance than muscle mass in older adults. Geriatr Gerontol Int 16: 577-585.

8. Manini TM, Clark BC (2012) Dynapenia and aging: an update. J Gerontol A Biol Sci Med Sci 67: 28-40.

9. McLean RR, Shardell MD, Alley DE, Cawthon PM, Fragala MS, et al. (2014) Criteria for clinically relevant weakness and low lean mass and their longitudinal association with incident mobility impairment and mortality: the Foundation for the National Institutes of Health (FNIH) sarcopenia project. J Gerontol A Biol Sci 69: 576-583.

10. Buchholz TG (2016) The real threat of an aging population. TIME June 06.

11. Thompson $D$ (2016) The invisible revolution: how aging is quietly changing America. The Atlantic October, USA.

12. Department of Economic and Social Affairs, Population Division (2017) 
World Population Prospects The 2017 Revision: Key Findings and Advance Tables. Working Paper No: ESA/P/WP/248, United Nations, New York, USA.

13. Seals DR, Justice JN, LaRocca TJ (2016) Physiological geroscience: targeting function to increase healthspan and achieve optimal longevity. J Physiol 594: 2001-2024.

14. McCracken H, Grossman L (2013) The Audacity of Google. Larry Page and the art of the moon shot. Time International (South Pacific Edition) 182: 22-30.

15. Anton SD, Woods AJ, Ashizawa T, Barb D, Buford TW, et al. (2015) Successful aging: advancing the science of physical independence in older adults. Ageing Res Rev 24: 304-327.

16. Dulac M, El-Haji BG, Pion C, Barbat-Artigas S, Gouspillou G, et al (2016) Is handgrip strength normalized to body weight a useful tool to identify dynapenia and functional incapacity in postmenopausal women? Braz J Phys Ther 20: 510-516.

17. Rossi AP, Fantin F, Caliari C, Zoico E, Mazzali G, et al. (2016) Dynapenic abdominal obesity as predictor of mortality and disability worsening in older adults: a 10-year prospective study. Clin Nutr 35: 199-204.

18. Santos DL, Cyrino ES, Antunes M, Santos DA, Sardinha LB (2017) Sarcopenia and physical independence in older adults: the independent and synergic role of muscle mass and muscle function. J Cachexia Sarcopenia Muscle 8: 245-250.

19. Fritz NE, McCarthy CJ, Adamo DE (2017) Handgrip strength as a means of monitoring progression of cognitive decline - a scoping review. Ageing Res Rev 35: 112-123.

20. Matsui Y, Takemura M, Harada A, Ando F, Shimokata H (2014) Effects of knee extensor muscle strength on the incidence of osteopenia and osteoporosis after 6 years. J Bone Miner Metab 32: 550-555.

21. Leong DP, Teo KK, Rangarajan S, Lopez-Jaramillo P, Avezum A Jr, et al. (2015) Prognostic value of grip strength: findings from the Prospective Urban Rural Epidemiology (PURE) study. Lancet 386: 266-273.

22. Cuthbertson DJ, Bell JA, Ng SY, Kemp GJ, Kivimaki M, et al. (2016) Dynapenic obesity and the risk of incident type 2 diabetes: the English Longitudinal Study of Ageing. Diabet Med 33: 1052-1059.

23. Ling CH, Taikema D, de Craen AJ, Gussekloo J, Westendorp RG, et al. (2010) Handgrip strength and mortality in the oldest population: the Leiden 85-plus study. CMAJ 182: 429-435.

24. Ortega FB, Silventoinen K, Tynelius P, Rasmussen F (2012) Muscular strength in male adolescents and premature death: cohort study of one million participants. BMJ 345: 7279.

25. Ruiz JR, Sui X, Lobelo F, Morrow JR, Jackson, et al. (2008) Association between muscular strength and mortality in men: prospective cohort study. BMJ 337: 439

26. Haskell WL, Lee IM, Pate RR, Powell KE, Blair SN, et al. (2007) Physical activity and public health: updated recommendation for adults from the American College of Sports Medicine and the American Heart Association. Med Sci Sports Exerc 39: 1423-1434.

27. Nelson ME, Rejeski WJ, Blair SN, Duncan PW, Judge JO, et al. (2007) Physical activity and public health in older adults: recommendation from the American College of Sports Medicine and the American Heart Association. Med Sci Sports Exerc 39: 1435-1445.

28. Kraschnewski JL, Sciamanna CN, Poger JM, Rovniak LS, Lehman
EB, et al. (2016) Is strength training associated with mortality benefits? A 15year cohort study of US older adults. Prev Med 87: 121-127.

29. Kraschnewski JL, Sciamanna CN, Ciccolo JT, Rovniak LS, Lehman EB, et al. (2014) Is exercise used as medicine? Association of meeting strength training guidelines and functional limitations among US older adults. Prev Med 66: 1-5.

30. American College of Sports Medicine and American Medical Association (2007) ACSM and AMA launch "Exercise is Medicine" program, Indiana, USA.

31. Colberg SR, Sigal RJ, Fernhall B, Regensteiner JG, Blissmer BJ, et al. (2010) Exercise and type 2 diabetes. The American College of Sports Medicine and American Diabetes Association: joint position statement. Diabetes Care 33: 147-167.

32. Williams MA, Haskell WL, Ades PA, Amsterdam EA, Bittner V, et al. (2007) Resistance exercise in individuals with and without cardiovascular disease: 2007 update: a scientific statement from the American Heart Association Council on Clinical Cardiology and Council on Nutrition, Physical Activity, and Metabolism. Circulation 116: 572-584.

33. American College of Sports Medicine (2009) Progression models in resistance training for healthy adults. Med Sci Sports Exerc 41 : 687-708.

34. American Geriatrics Society (2001) Exercise prescription for older adults with osteoarthritis pain: consensus practice recommendations. A supplement to the AGS clinical practice guidelines on the management of chronic pain in older adults. J Am Gerriatr Soc 49: 808-823.

35. Law TD, Clark LA, Clark BC (2016) Resistance exercise to prevent and manage sarcopenia and dynapenia. Annu Rev Gerontol 36: 205-228.

36. American College of Sports Medicine (2016) ACSM's Research Methods. In: Armstrong LE, Kraemer WJ (eds.). ACSM's Research Methods. Wolters Kluwer, Philadelphia, USA. Pg no: 97-98.

37. Borde R, Hortbagyi T, Granacher U (2015) Dose-response relationships of resistance training in healthy old adults: a systematic review and meta-analysis. Sports Med 45: 1693-1720.

38. Liu CJ, Latham NK (2009) Progressive resistance training for improving physical function in older adults. Cochrane Database Syst Rev 3: 2759.

39. Peterson MD, Rhea MR, Sen A, Gordon PM (2010) Resistance exercise for muscular strength in older adults: a meta-analysis. Ageing Res Rev 9: 226-237.

40. Silva NL, Oliveira RB, Fleck SJ, Leon AC, Farinatti P (2014) Influence of strength training variables on strength gains in adults over 55 years-old: a meta-analysis of dose-response relationships. J Sci Med Sport 17: 337-344.

41. Steib S, Schoene D, Pfeifer K (2010) Dose-response relationship of resistance training in older adults: a meta-analysis. Med Sci Sports Exerc 42: 902-914.

42. Chodzko-Zajko WJ, Proctor DN, Fiatarone Simgh MA, Minson CT, Nigg CR, et al. (2009) American College of Sports Medicine position stand. Exercise and physical activity for older adults. Med Sci Sports Exerc 41: 1510-1530.

43. Faigenbaum AD, MacDonald JP (2017) Dynapenia: it's not just for grown-ups anymore. Acta Paediatrica 106: 696-697.

44. Lobelo F, Kelli HM, Tejedor SC, Pratt M, McConnell MV, et al. (2016) The wild wild west: a framework to integrate mhealth software ap- 
Citation: Williams DP (2017) Strength Training for the Prevention and Treatment of Dynapenia. J Bone Muscles Stud 2017: 13-21.

plications and wearables to support physical activity assessment counseling, and interventions for cardiovascular disease risk reduction.

Prog Cardiovasc Dis 58: 584-594.

45. Nishiyama Y, Okoshi T, Yonezawa T, Nakazawa J, Takashio K, et al. (2016) Toward health exercise behavior change for teams using lifelog sharing models. IEEE J Biomed Health Inform 20: 775-786.

46. Balsalobre-Fernández C, Marchante D, Baz-Valle E, Alonso-Molero I,
Jiménez SL, et al. (2017) Analysis of wearable and smartphone-based technologies for the measurement of barbell velocity in different resistance training exercises. Front Physiol 8: 649.

47. Bouchard C, Blair SN, Katzmarzyk PT (2015) Less sitting, more physical activity, or higher fitness? Mayo Clin Proc 90: 1533-1540.

48. Ng SW, Popkin B (2012) Time use and physical activity: a shift away from movement across the globe. Obese Rev 13: 659-680. 